\title{
p63 in Laryngeal Squamous Cell Carcinoma: Evidence for a Role of TA-p63 Down-Regulation in Tumorigenesis and Lack of Prognostic Implications of p63 Immunoreactivity
}

\author{
Giancarlo Pruneri, Lorenzo Pignataro, Michela Manzotti, Nadia Carboni, \\ Domenica Ronchetti, Antonino Neri, Bruno Mario Cesana, and Giuseppe Viale
}

Divisions of Pathology and Laboratory Medicine, European Institute of Oncology and University of Milan School of Medicine (GP, MM, GV), and 1st Department of Otolaryngology (LP), 3rd Division of Internal Medicine (NC), Laboratory of Experimental Hematology and Molecular Genetics (DR, AN), and Epidemiologic Unit (BMC), Ospedale Maggiore, Istituto di Ricovero e Cura a Carattere Scientifico, University of Milan, School of Medicine, Milan, Italy

\begin{abstract}
SUMMARY: $p 63$ is a p53-related gene that encodes for multiple mRNA transcripts with (TA-p63) or without ( $\Delta \mathrm{N}$-p63) transactivating properties on p53-responsive genes. We evaluated for the first time the prevalence and clinical implications of p63 immunoreactivity (IR) and mRNA expression in laryngeal squamous cell carcinomas (LSCCs). Moreover, we also assessed the relationships between p63 expression and p53 gene status. p63 IR was detectable in the basal cell layers of non-neoplastic epithelium and in the whole thickness of dysplastic epithelium. All the 150 LSCCs analyzed were immunoreactive for p63, with $28(18.7 \%)$ cases showing p63 IR in $\leq 50 \%$ of neoplastic cells. $\Delta \mathrm{N}$-p63 mRNA transcripts were detected in all the 23 tumors analyzed, whereas TA-p63 mRNA transcripts were absent in $5(21.7 \%)$ cases. p53 gene mutations were found in $24(29.2 \%)$ of the 82 cases analyzed and p53 IR was found in $58(53.7 \%)$ of the 108 cases analyzed; neither was associated with p63 IR. No significant association was found between p63 IR and patients' survival. Interestingly, down-regulation of TA-p63 mRNA levels was more prevalent in patients with T3-T4 tumors and advanced clinical stage. Although the risk of death for cancer was higher in these patients (40\% versus $16.6 \%)$, this difference did not reach statistical significance. Our results suggest that abnormal expression of p63 may be involved in the early phases of laryngeal tumorigenesis irrespective of p53 gene status and that TA-p63 mRNA down-regulation, but not p63 IR, may be clinically relevant in patients with LSCC. (Lab Invest 2002, 82:1327-1334).
\end{abstract}

p63/p73L/p51/p40/CUSP/KET is a recently cloned p53related gene mapping to chromosome $3 q 27-29$, which shares structural and functional homologies with the p53 family of transcription factors. Accordingly, p63 is capable of binding DNA, transactivating p53-responsive genes, and inducing apoptosis (Levrero et al, 2000). At variance with $\mathrm{p} 53$, p63 codes for multiple mRNA transcripts under two different promoters and via three alternative splicing modalities of the C-terminal ends. In particular, TA-p63 $\alpha, \beta$, and $\gamma$ have transactivating properties, whereas $\Delta \mathrm{N}-\mathrm{p} 63 \alpha, \beta$, and $\gamma$ lack the $\mathrm{NH}_{2}$-terminal transactivation domain and function as dominant negative proteins, capable of blocking the activities of the full-length homologs (Yang et al, 1998).

p63 does not seem to play a major role as a tumor suppressor gene, because it is rarely mutated in

DOI: 10.1097/01.LAB.0000032373.99569.73

Received April 22, 2002.

This work was supported by grants from the Associazione Italiana sul Cancro (to AN and GV). GP and LP contributed equally to this work.

Address reprint requests to: Dr. G. Viale, Division of Pathology and Laboratory Medicine, European Institute of Oncology, via Ripamonti 435, 20141, Milan, Italy.E-mail: giuseppe.viale@ieo.it primary tumors (Nishi et al, 1999; Sunahara et al, 1999; Tani et al, 1999) and in cancer cell lines (Hagiwara et al, 1999). Nevertheless, p63 mRNA and/or protein are overexpressed in a variety of human neoplasms as a result of gene amplification (Barbareschi et al, 2001; Glickman et al, 2001; Hibi et al, 2000; Park et al, 2000; Wang et al, 2001). p40 (a p63 isoform lacking the $\mathrm{N}$-terminal transactivation domain) is tumorigenic when transfected into rat fibroblasts (Hibi et al, 2000). These data strongly suggest that p63 gene aberrations may be involved in human tumorigenesis.

Given that p63 gene aberrations are common in squamous cell carcinomas arising in the head and neck region (Hibi et al, 2000; Yamaguchi et al, 2000), we evaluated the prevalence and clinical implications of p63 immunoreactivity (IR) and mRNA expression in a cohort of patients with laryngeal squamous cell carcinomas (LSCCs). Moreover, we also assessed the relationships between p63 expression and p53 gene status. Our results document that abnormal expression of $p 63$ may be involved in the early phases of laryngeal tumorigenesis irrespective of p53 gene status and suggest that TA-p63 mRNA down-regulation, but not p63 IR, may be clinically relevant in patients with LSCC. 


\section{Results}

\section{p63 IR and mRNA Expression}

In normal laryngeal mucosa, nuclear IR for p63 was detectable in the basal and suprabasal layers of the epithelium and in myoepithelial cells of the seromucinous glands (Fig. 1A). In laryngeal intraepithelial neoplasia (LIN) p63 IR was no longer restricted to the basal cell layers, being detectable throughout the full thickness of the dysplastic epithelium (Fig. 1B).

p63 immunostaining was detected in the neoplastic cells of all the 150 LSCCs analyzed, with a percentage of immunoreactive cells ranging from $10 \%$ to $98 \%$ (mean $78.2 \pm 20.8 \%$, median 88.5\%) (Fig. 1, C and D).
In particular, 28 (18.7\%) cases showed nuclear IR in $\leq 50 \%$ of neoplastic cells and $122(81.3 \%)$ showed nuclear IR in $>50 \%$. In the 10 cases investigated for both p63 and p40 IR, no differences in immunostaining were detected either in normal and dysplastic mucosa or in invasive carcinoma (Fig. 1, E to H).

TA-p63 and $\triangle \mathrm{N}$-p63 mRNA expression were analyzed in $23(15.3 \%)$ LSCCs and in 4 samples of non-neoplastic mucosa. $\Delta \mathrm{N}$-p63 mRNA transcripts were detected in all the tumors analyzed, whereas TA-p63 mRNA transcripts were absent in five (21.7\%) cases (Fig. 2). Three of the latter cases showed p63 IR in $>50 \%$ of the neoplastic cells and one (KL52) showed a p53 gene missense mutation in codon 245.

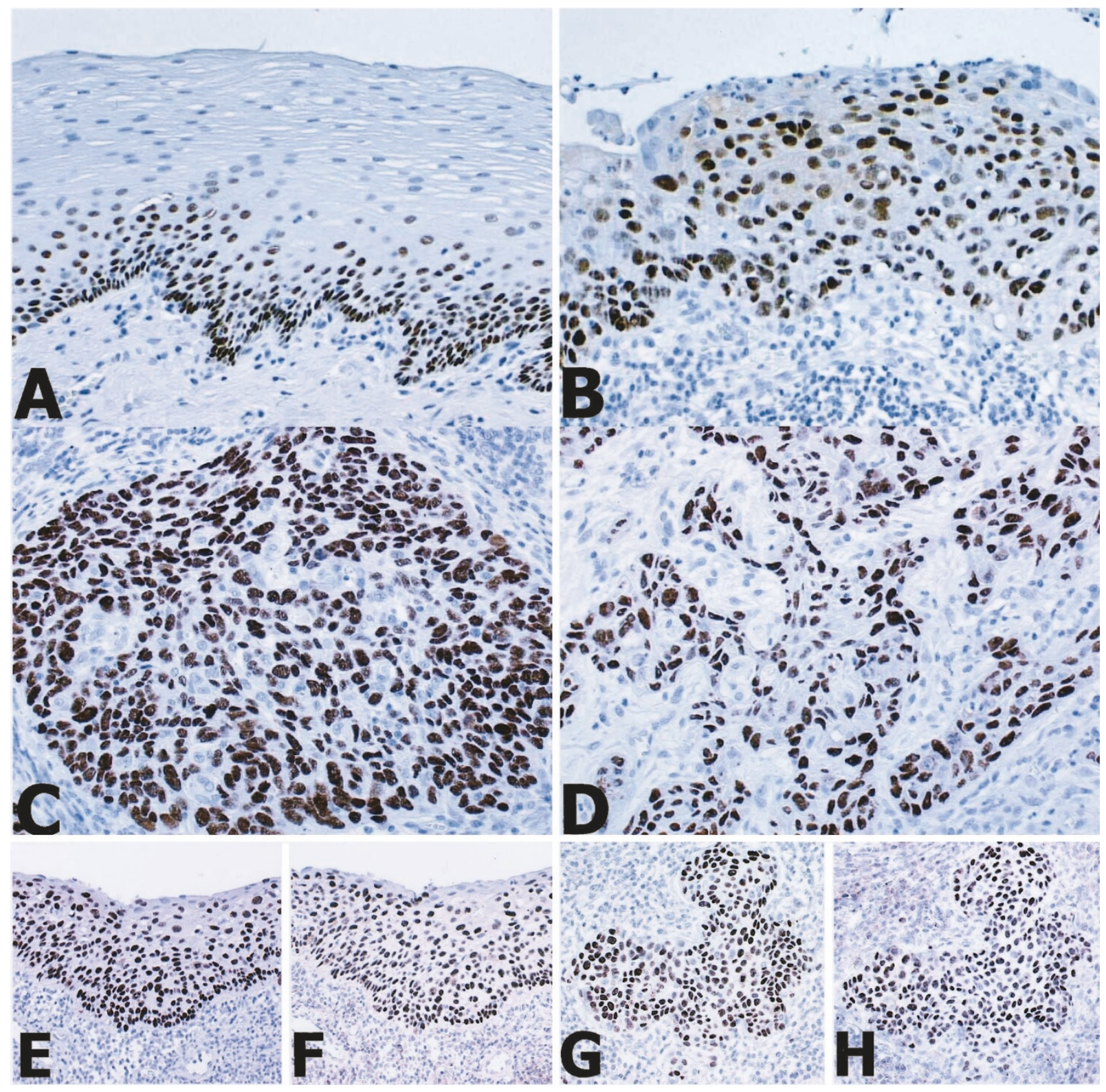

Figure 1.

Examples of the immunohistochemical results. Immunoreactivity for $p 63$ is restricted to the basal and suprabasal layers in normal laryngeal epithelium (A), whereas it is detectable throughout the full thickness of the dysplastic epithelium (B). C and D, Two different cases of laryngeal squamous cell carcinoma (LSCC) diffusely immunoreactive for p63. Serial sections of dysplastic mucosa (E and F) and invasive carcinoma (G and H) immunostained with the anti-p63 (left) and p40 (right) antibodies document colocalization of p40 and p63 antigens. Original magnification, $\times 250$; hematoxylin counterstain. 

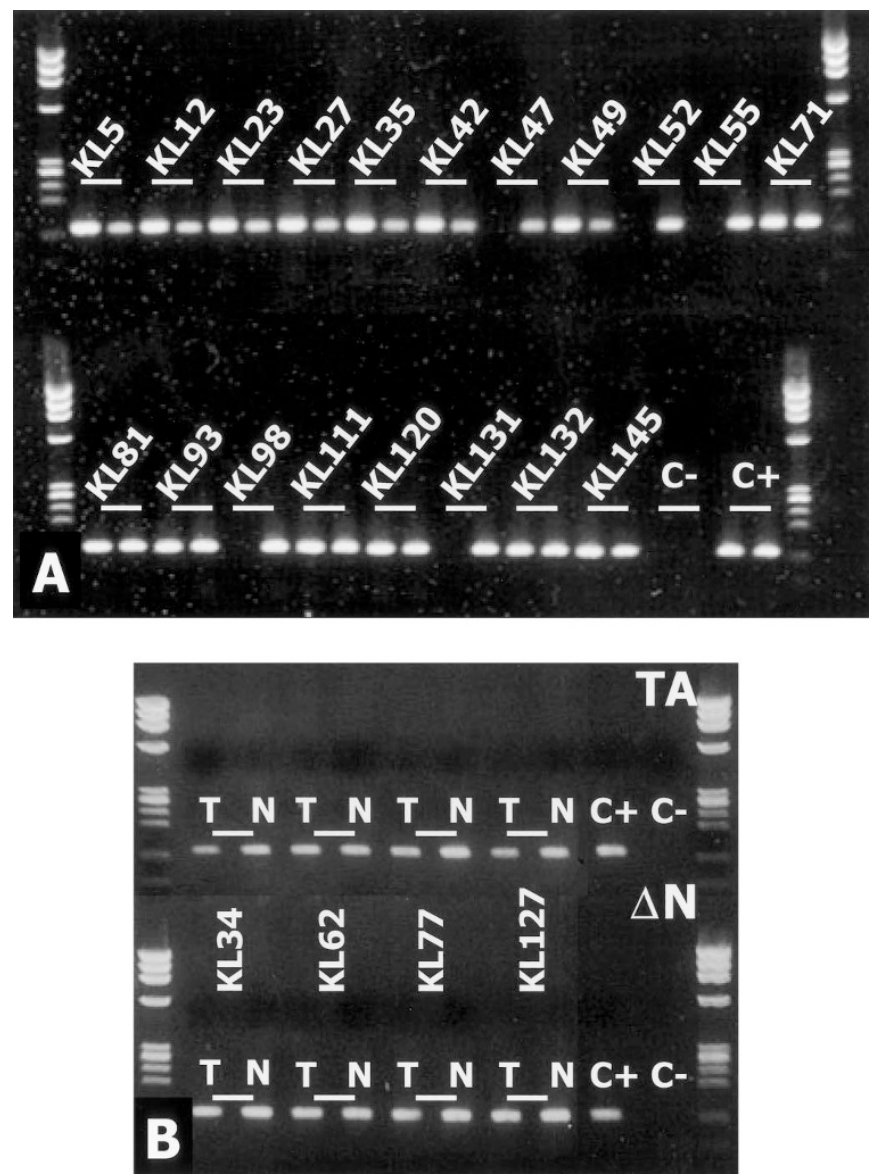

Figure 2.

Results of the RT-PCR assay in the 23 LSCCs (KL) analyzed. A, RT-PCR products of TA-p63 (left lanes) and $\triangle \mathrm{N}$-p63 (right lanes) in 19 cases of LSCC are shown. In cases KL47, KL52, KL55, KL98, and KL131, TA-p63 mRNA is lacking. B, RT-PCR levels of TA-p63 (upper lanes) and $\Delta \mathrm{N}$-p63 (lower lanes) in four cases of KL $(T)$ and corresponding non-neoplastic mucosa $(M$. All the cases of T and N bear similar amounts of TA-p63 and $\Delta N-p 63$ mRNA.

All the samples of non-neoplastic mucosa showed high levels of both TA-p63 and $\triangle \mathrm{N}$-p63 mRNA expression (Fig. 2).

\section{Correlations Between p63 Expression and p53 Gene Status}

Abnormally migrating bands after PCR/single-strand conformation polymorphism (SSCP) experiments were identified in 24 (29.2\%) of the 82 cases analyzed. p53 gene mutations had been previously investigated in 18 LSSCs included in the current series (Pruneri et al, 1996). In particular, there were nine mutations in exon 5 , four in exon 6 , six in exon 7 , and five in exon 8. Twenty-one mutated genes showed single-base substitutions, two insertions, and one deletion (Table 1). Fourteen (58.3\%) mutations mapped to the DNA binding domain necessary for the physiologic activity of p53 as a tumor suppressor. In particular, nine mutations occurred in the large loop L2 (residues 163-195) and five mutations in the loop L3 (residues 236-251). Point mutations included 10 transitions and 11 transversions, with the $\mathrm{G}>\mathrm{T}$ transversion being the most common mutational event (33\%).

Nuclear IR for p53 had been previously analyzed in $108(72 \%)$ cases included in the present series and was found in 58 (53.7\%) cases (Pruneri et al, 1998). No associations were documented between p63 IR and p53 protein accumulation $(p=0.844)$ or gene mutations $(p=0.754)$, either in the whole series of cases (Table 2) or when only the tumors carrying mutations in the transactivating domain were taken into account.

\section{Clinicopathologic Correlates and Prognostic Implications of p63 and p53 Abnormalities}

Among the clinicopathologic characteristics analyzed, low $(\leq 50 \%)$ IR for p63 was associated at a borderline level of statistical significance with the pattern of tumor growth $(p=0.066)$ and alcohol consumption $(p=0.059)$ (Table 3).

At univariate analyses, anatomic site $(p=0.0013)$, lymph node metastases $(p=0.0147)$, tumor extension $(p=0.0016)$, clinical stage $(p=0.0013)$, tobacco use $(p=0.0015)$, and alcohol consumption $(p=0.0217)$ were significantly associated with tumor recurrence. At multivariate analysis, tumor extension $(p=0.0319)$, anatomic site $(p=0.0088)$, and tobacco use $(p=$ 0.0240 ) were the only significant independent predictors of disease free-survival.

Anatomic site $(p=0.0109)$, tumor extension $(p=0.0052)$, clinical stage $(p=0.0014)$, tobacco 
Table 1. p53 Gene Mutations

\begin{tabular}{lccc}
\hline Sample & Type of mutation & Codon & Base substitution \\
\hline KL2 & Missense & 267 & C:G-to-T:A \\
KL5 & Missense & 248 & G:C-to-A:T \\
KL12 & Missense & 177 & C:G-to-T:A \\
KL23 & Missense & 196 & C:G-to-T:A \\
KL27 & Missense & 175 & G:C-to-A:T \\
KL30 & Missense & 238 & G:C-to-A:T \\
KL32 & Missense & 278 & C:G-to-T:A \\
KL33 & Nonsense & 306 & C:G-to-T:A \\
KL39 & Splicing & 187 & G:C-to-T:A \\
KL41 & Missense & 176 & G:C-to-T:A \\
KL46 & Missense & 176 & G:C-to-T:A \\
KL52 & Missense & 245 & G:C-to-T:A \\
KL76 & Missense & 157 & G:C-to-T:A \\
KL82 & Missense & 277 & G:C-to-T:A \\
KL91 & Missense & 273 & G:C-to-T:A \\
KL97 & Missense & 237 & G:C-to-C:G \\
KL101 & Missense & 141 & G:C-to-C:G \\
KL106 & Missense & 193 & A:T-to-T:A \\
KL115 & Missense & 239 & A:T-to-G:C \\
KL119 & Missense & 214 & A:T-to-G:C \\
KL126 & Insertion & 177 & - \\
KL133 & Insertion & 162 & G:C-to-T:A \\
KL138 & Splicing & 187 & - \\
KL143 & Deletion & 259 &
\end{tabular}

Table 2. Comparison Between p63 IR and p53 Gene Status or Protein Accumulation

\begin{tabular}{crcc}
\hline & $p 63 \leq$ & $p 63>$ & \\
& \multicolumn{1}{c}{$50 \%$} & $50 \%$ & $p$ \\
\hline Patients (\%)-p53 gene & $17(20.7 \%)$ & $65(79.3 \%)$ & \\
Wild-type (58, 70.7\%) & $11(64.7 \%)$ & $47(72.3 \%)$ & \\
Mutated (24, 29.3\%) & $6(35.3 \%)$ & $18(27.7 \%)$ & 0.754 \\
Patients (\%)-p53 IR & $17(15.7 \%)$ & $91(84.3 \%)$ & \\
Negative (50, 46.3\%) & $7(41.2 \%)$ & $43(47.3 \%)$ & \\
Positive (58, 53.8\%) & $10(58.8 \%)$ & $48(52.7 \%)$ & 0.844 \\
\hline
\end{tabular}

use $(p=0.0138)$ and, at a borderline level of statistical significance, alcohol consumption $(p=$ $0.0539)$ were associated with reduced overall survival. The Cox proportional hazards model, including all the clinicopathologic variables that were significant at univariate analysis, showed that clinical stage $(p=0.0165)$, tobacco use $(p=0.0428)$ and, at a borderline level of statistical significance, anatomic site $(p=0.0662)$ were the only independent covariates.

There was no correlation between p63 IR and disease-free $(p=0.5017)$ or overall survival $(p=$ $0.3491)$, although patients with high (>50\%) p63 IR were at greater risk for tumor recurrence and death than patients with low ( $\leq 50 \%)$ p63 IR $(35.2 \%$ versus $28.6 \%$ and $31.2 \%$ versus $25 \%$, respectively) (Table 4 ). In the subset of 23 patients analyzed by RT-PCR, down-regulation of TA-p63 mRNA levels was more prevalent in patients with T3-T4 tumors and advanced clinical stage, at a borderline level of statistical signif- icance $(p=0.0783$ and $p=0.0662)$. Although the risk of death for cancer was higher in these patients $(40 \%$ versus $16.6 \%$ ), this difference did not reach statistical significance ( $p=0.3689$ ).

No statistical difference in overall survival was found between the patients with mutated and wild-type p53 gene $(62.5 \%$ versus $63.3 \%, p=1.000)$. Patients with p53 gene mutations showed a higher probability of tumor recurrence $(50 \%)$ than those with wild-type p53 (40\%), although this difference did not reach statistical significance $(p=0.468)$.

\section{Discussion}

In this study, we have investigated p63 expression in a homogeneous and well-characterized series of patients with LSCCs. p63 plays a pivotal role in ectodermal differentiation, as demonstrated by the fact that p63 knockout mice show major defects in their limb, craniofacial, and epithelial development (Mills et al, 1999; Yang et al, 1999). We document TA-p63 and $\Delta \mathrm{N}$-p63 expression in all the samples of normal laryngeal mucosa, where it is restricted to the basal and suprabasal epithelial cell layers. Similar findings have been recently reported in oral (Nylander et al, 2000) and esophageal (Suliman et al, 2001) epithelia. Because transactivating and truncated p63 isoforms show opposite effects in regulating proapoptotic and differentiating genes, such as p21 and bax (Irwin and Kaelin, 2001), these data suggest that the process of epithelial differentiation at these sites depends on a dynamic balance between TA-p63 and $\Delta \mathrm{N}-\mathrm{p} 63$ isoforms.

We found a very high prevalence of p63 IR in LSCC, in keeping with recent data in pulmonary squamous cell carcinoma (Pelosi et al, 2002). Interestingly, the $3 q 27-29$ chromosomal region, where p63 is located, is the most frequently overrepresented genomic locus in head and neck cancer (Speicher et al, 1995), and most of the head and neck carcinomas show amplification of the p40/p51/p63 locus by fluorescence in situ hybridization analysis (Hibi et al, 2000; Yamaguchi et al, 2000). Taken together, these data suggest that an abnormal status and expression of the p63 gene may play a pivotal role in the multiple stage model of laryngeal tumorigenesis, although data concerning p63 abnormalities in preinvasive lesions are still lacking. The accumulation of p63 immunoreactive cells in laryngeal intraepithelial neoplasia allows for speculation that p63 gene abnormalities may be involved in the very early steps of laryngeal cancer development, in a similar manner as for p53.

We also evaluated the clinical implications of p63 deregulation in patients with laryngeal carcinomas, showing a greater probability (although without attaining statistical significance) of tumor recurrence and death in patients with higher p63 IR. Similar results have been recently reported in patients with pulmonary squamous cell carcinoma (Pelosi et al, 2002), emphasizing that p63 IR has minimal, if any, clinical relevance in these settings. It has been suggested that the biologic effects of p63 depend 
Table 3. Comparison Between p63 IR and Clinicopathologic Characteristics

\begin{tabular}{|c|c|c|c|}
\hline & $p 63 \leq 50 \%$ & $p 63>50 \%$ & $p$ \\
\hline Patients (\%) & $28(18.7 \%)$ & $122(81.3 \%)$ & \\
\hline \multicolumn{4}{|l|}{ Gender } \\
\hline Men $(144,96 \%)$ & $27(96.4 \%)$ & $117(95.9 \%)$ & \\
\hline Women $(6,4 \%)$ & $1(3.6 \%)$ & $5(4.1 \%)$ & 1.000 \\
\hline \multicolumn{4}{|l|}{ Age } \\
\hline$\leq 60(65,43.3 \%)$ & $16(57.1 \%)$ & $49(40.1 \%)$ & \\
\hline$>60(85,56.7 \%)$ & $12(42.9 \%)$ & $73(59.9 \%)$ & 0.155 \\
\hline \multicolumn{4}{|l|}{ Anatomical site } \\
\hline SG $(80,53.3 \%)$ & $15(53.6 \%)$ & $65(53.3 \%)$ & \\
\hline GL $(70,46.7 \%)$ & $13(46.4 \%)$ & $57(46.7 \%)$ & 1.000 \\
\hline \multicolumn{4}{|l|}{ Histologic grade } \\
\hline G1 $(26,17.3 \%)$ & $4(14.3 \%)$ & $22(18.1 \%)$ & \\
\hline G2 $(74,49.4 \%)$ & $13(46.4 \%)$ & $61(50 \%)$ & \\
\hline G3 $(50,33.3 \%)$ & $11(39.3 \%)$ & $39(31.9 \%)$ & 0.737 \\
\hline \multicolumn{4}{|l|}{ Tumor growth } \\
\hline Infiltrating (57, 38\%) & $16(57.1 \%)$ & $41(33.6 \%)$ & \\
\hline Exophytic $(66,44 \%)$ & $9(32.1 \%)$ & $57(46.7 \%)$ & \\
\hline Infiltrating/exophytic (27, 18\%) & $3(10.8 \%)$ & $24(19.7 \%)$ & 0.066 \\
\hline \multicolumn{4}{|l|}{ Tumor extension } \\
\hline T1-T2 (90, 60\%) & $16(57.1 \%)$ & $74(60.7 \%)$ & \\
\hline T3-T4 (60, 40\%) & $12(42.9 \%)$ & $48(39.3 \%)$ & 0.898 \\
\hline \multicolumn{4}{|l|}{ Lymph node } \\
\hline NO $(105,70 \%)$ & $21(75 \%)$ & $84(68.8 \%)$ & \\
\hline $\mathrm{N}+(45,30 \%)$ & $7(25 \%)$ & $38(31.2 \%)$ & 0.681 \\
\hline \multicolumn{4}{|l|}{ Clinical stage } \\
\hline$|-| \mid(77,51.3 \%)$ & $15(53.65)$ & $62(50.8 \%)$ & \\
\hline III-IV $(73,48.7 \%)$ & $13(46.4 \%)$ & $60(49.2 \%)$ & 0.958 \\
\hline \multicolumn{4}{|l|}{ Tobacco exposure } \\
\hline $0-19(47,31.3 \%)$ & $7(25 \%)$ & $40(32.8 \%)$ & \\
\hline $20-45(54,36 \%)$ & $11(39.3 \%)$ & $43(35.2 \%)$ & \\
\hline$>45(49,32.7 \%)$ & $10(35.7 \%)$ & $39(32 \%)$ & 0.725 \\
\hline \multicolumn{4}{|l|}{ Alcohol exposure } \\
\hline No/moderate $(75,50 \%)$ & $9(32.1 \%)$ & $66(54.1 \%)$ & \\
\hline Heavy $(75,50 \%)$ & $19(67.9 \%)$ & $56(45.9 \%)$ & 0.059 \\
\hline
\end{tabular}

SG, supraglottic; GL, glottic; G1, well differentiated; G2, moderately differentiated; G3, poorly differentiated; N0, negative lymph nodes; $\mathrm{N}+$, metastatic lymph nodes.

Table 4. p63 IR and Survival

\begin{tabular}{lccc}
\hline & $p 63 \leq$ & & \\
& $50 \%$ & $p 63>50 \%$ & $p$ \\
\hline Patients (\%) & $28(18.7 \%)$ & $122(81.3 \%)$ & \\
Overall survival & & & \\
NED (104, 69.3\%) & $21(75 \%)$ & $75(61.4 \%)$ & \\
DOD (40, 26.7\%) & $7(25 \%)$ & $38(31.2 \%)$ & \\
DWD (6, 4\%) & 0 & $9(7.4 \%)$ & 0.3491 \\
Tumor recurrence & & & \\
No (102, 68\%) & $20(71.4 \%)$ & $79(64.8 \%)$ & \\
Yes $(48,32 \%)$ & $8(28.6 \%)$ & $43(35.2 \%)$ & 0.5017 \\
\hline
\end{tabular}

NED, no evidence of disease; DOD, dead of disease; DWD, dead for other causes.

on the relative expression of either transactivating or truncated isoforms. We found detectable levels of $\Delta \mathrm{N}$-p63 expression in all the 23 LSCCs analyzed. By contrast, approximately $22 \%$ of the cases showed down-regulation of TA-p63 expression, similarly to primary bladder carcinomas (Park et al, 2000). $\Delta \mathrm{N}$ - p63 isoforms act as a dominant-negative factor on G1 cell-cycle arrest and apoptosis (Yang et al, 1998); accordingly, their relative increase may confer a growth advantage to the tumor cells. Downregulated TA-p63 expression has been associated with a higher risk of tumor recurrence and death in bladder carcinoma patients (Park et al, 2000), whereas in the current series it correlated with an advanced tumor stage at a borderline level of statistical significance. Although the rate of death for cancer was higher in patients with LSCC who had down-regulated TA-p63, this difference did not reach statistical significance, possibly because of the small number of patients analyzed.

There is evidence that some mutant forms of p53 are capable of down-regulating p63 in vitro through a direct interaction with the p53 core domain (Gaiddon et al, 2001). We did not find any relationship between p53 gene status or protein accumulation and p63 expression, either in the whole series of patients or taking into account only patients with mutations in the p53 transactivating domain. Likewise, Hibi et al (2000) 
reported that $\mathrm{p} 40$ amplification and p53 gene mutations occur simultaneously in most of the pulmonary squamous cell carcinomas. Taken together, these data suggest that p53 and p63 gene abnormalities occur independently in human tumors and are not mutually exclusive.

\section{Patients and Methods}

\section{Patients and Tissues}

One-hundred fifty patients were included in the current study, according to the following criteria: no history of previous malignancies, primary squamous cell carcinoma of the larynx only, no previous radiotherapy or chemotherapy, and complete surgical excision of the tumor by means of partial (69 patients, $46 \%$ ) or total laryngectomy (81 patients, $54 \%$ ). There were $144(96 \%)$ men, with a mean age of $61.5 \pm 9.52$ (range, 33-81; median, 62) years. All of the patients had been exposed to risk factors such as tobacco use and/or alcohol consumption. They were grouped into three classes on the basis of the number of packyears of smoking $(0-19,20-45$, and $>45)$ : $47(31.3 \%)$ patients had smoked 0-19 pack-years; 54 (36\%) patients, 20-45 pack-years; and 49 (32.7\%) patients, $>45$ pack-years. Seventy-five $(50 \%)$ patients were classified as heavy drinkers ( $\geq 7$ drinks per day, one drink corresponding to $150 \mathrm{ml}$ of wine or $30 \mathrm{ml}$ of hard liquor), and $75(50 \%)$ as moderate ( $<7$ drinks per day/nondrinkers).

The clinical staging and identification of the anatomical site of the tumors were based on the UICC (1987) TNM Classification of Malignant Tumors: 80 (53.3\%) were supraglottic and $70(46.7 \%)$ glottic. Thirty-eight $(25.3 \%)$ were in Stage I, $39(26 \%)$ in Stage II, 31 $(20.7 \%)$ in Stage III, and $42(28 \%)$ in Stage IV. Diagnosis and assessment of the grade of differentiation of the tumors showed that there were 26 welldifferentiated (G1, 17.3\%), 74 moderately differentiated (G2, 49.4\%), and 50 poorly differentiated (G3, $33.3 \%$ ) squamous cell carcinomas (Shanmugaratnam and Sobin, 1987).

The follow-up of the patients ranged from 4 to 128 (mean, $86 \pm 57.7$; median, 76) months. During the follow-up period, 51 (34\%) patients had tumor relapse, $45(30 \%)$ died because of the disease, and 9 $(6 \%)$ died for unrelated causes. Of the 96 surviving patients, $89(92.7 \%)$ were free of disease, and 7 (7.3\%) were alive with disease.

For all patients, samples of the invasive tumors and of adjacent normal mucosa and/or laryngeal intraepithelial neoplasia (LIN1-3) were retrieved from the surgical pathology files of the 1st Department of Otolaryngology, Ospedale Maggiore, and of the Department of Pathology and Laboratory Medicine of the European Institute of Oncology, University of Milan School of Medicine. Frozen tissue samples of invasive carcinoma and non-neoplastic mucosa were also available in 82 and 4 cases, respectively. Written informed consent was obtained from each patient included in the study.

\section{Immunohistochemistry}

The immunohistochemical experiments were performed on $4-\mu \mathrm{m}$-thick formalin-fixed and paraffinembedded tissue sections by means of the avidinbiotin peroxidase complex method using 3,3'diaminobenzidine tetrahydrochloride chromogen (Pruneri et al, 2000). The sections were immunostained using the $4 \mathrm{~A} 4 \mathrm{mAb}$ (courtesy of Dr. Jon Askaa, DAKO A/S, Glostrup, Denmark), which recognizes both the transactivating and the truncated p63 isoforms, at a working dilution of $2 \mu \mathrm{l} / \mathrm{ml}$. In 10 (6.6\%) cases, samples of LSCC, LIN, and normal mucosa were also immunostained with the anti-p40 Ab-1 polyclonal antibody (Oncogene Science, Boston, Massachusetts), specifically recognizing only the truncated isoforms of p63 (Hibi et al, 2000), at a working dilution of 1:16,000. In each case of LSCC, at least 500 neoplastic cells were evaluated at $\times 400$ magnification, and the percentage of immunoreactive cells was recorded. Control sections for specificity included known positive control tissues (myoepithelial cells of the breast for p63, Barbareschi et al, 2001; and infiltrating duct carcinoma of the breast for p40, according to the manufacturer's recommendations) and staining of serial sections of the test cases with an unrelated isotypic mouse monoclonal antibody (for p63) and normal rabbit serum (for p40), at the same working dilution, as negative controls.

\section{RT-PCR Analysis}

Total cellular RNA was isolated from frozen tissue samples of 23 LSSCs, using theTRIzol reagent (Invitrogen Corporation, Carlsbad, California), according to the manufacturer's instructions. One microgram of RNA was reverse transcribed with random examers. In four of these cases, samples of uninvolved mucosa were also analyzed. In all the cases, hematoxylin and eosin-stained slides were evaluated before and after mRNA extraction to ensure for the presence of tumor and non-neoplastic epithelium in the tissue used for reverse transcription. To check for the integrity of the obtained cDNA, the samples were first amplified for a 511 -bp $\beta$-actin sequence, using the specific primers BACT-2284F and BACT-3000R (5'-GAAATCGTGCGTGACATTAGG-3' and 5'-CTAGAAGCATTTGCGGTGGA-3') as previously reported (Manzotti et al, 2000). The samples were then amplified for the TA-p63 and $\Delta \mathrm{N}$-p63 isotypes using specific primers recognizing the $\alpha, \beta$, and $\gamma$ isoforms (TA-p63 forward: TGTATCCGCATGCAGGACT, reverse: CTGTGTTATAGGGACTGGTGGAC; $\triangle \mathrm{N}$-p63 forward: GAAAACAATGCCCAGACTCAA, reverse: TGCGCGTGGTCTGTGTTA). The primers spanned an intron to exclude annealing to genomic DNA, and the expected length of the amplified sequences was 126 and 125 bp for TA-p63 and $\Delta \mathrm{N}-\mathrm{p} 63$, respectively. Briefly, $2 \mu \mathrm{l}$ of cDNA were amplified in $50 \mu \mathrm{l}$ of $1 \times$ PCR buffer II, $1.5 \mathrm{~mm} \mathrm{MgCl}$ (Applied Biosystems, Foster City, California), $200 \mu \mathrm{M}$ dNTPs (Pharmacia, Uppsala, Sweden), $0.5 \mu \mathrm{m}$ of each primer, and $0.025 \mathrm{U} / \mu \mathrm{l}$ AmpliTaq DNA Polymerase 
(Applied Biosystems). The PCR conditions were the same for the two p63 mRNA isotypes: denaturation at $94^{\circ} \mathrm{C}$ for 30 seconds, annealing at $54^{\circ} \mathrm{C}$ for 30 seconds, and extension at $72^{\circ} \mathrm{C}$ for 30 seconds, for a total of 35 cycles. The PCR products were analyzed on a $2 \%$ agarose gel, stained with ethidium bromide.

\section{PCR/SSCP and Sequencing Experiments for p53 Gene Mutations}

PCR/SSCP and sequencing analyses for assessing p53 gene status were performed in 82 cases (Neri et al, 1993). Exons 5 to 8 of the p53 gene were separately amplified using specific oligonucleotide primers. Briefly, PCR was performed using $100 \mathrm{ng}$ of genomic DNA, $10 \mathrm{~mm}$ Tris- $\mathrm{HCl}(\mathrm{pH} 8.8), 50 \mathrm{~mm} \mathrm{KCl}, 1 \mathrm{~mm}$ $\mathrm{MgCl}_{2}, 100 \mu \mathrm{M}$ of each of the dNTPs, $0.25 \cup$ Taq DNA Polymerase, and $10 \mathrm{pmol}$ of each primer, in a final volume of $25 \mu \mathrm{l}$. Thirty cycles of denaturation (15 seconds at $94^{\circ} \mathrm{C}$ ), annealing ( 1 minute at $65^{\circ} \mathrm{C}$ for exons 5,6 , or 7 and at $58^{\circ} \mathrm{C}$ for exon 8), and extension ( 1 minute at $72^{\circ} \mathrm{C}$ ) were performed. Ten microliters of the reaction mixture was mixed with equal volume of a denaturing stop solution. Samples were heated at $95^{\circ} \mathrm{C}$ for 5 minutes, chilled on ice, and immediately loaded onto a $6 \%$ acrylamide-TBE gel. The samples were run at 6 to 8 watts constant power for 14 hours at room temperature. The detection was performed by the silver staining method. PCR products showing an aberrant migration pattern were directly sequenced in both directions using the $5^{\prime}$ and $3^{\prime}$ primers used for the PCR/SSCP analysis. The DNA fragments were purified by means of agarose gel extraction and sequenced using the Big Dye Terminator Sequencing Kit in an ABI Prism 310 automated sequencer (Perkin Elmer Cetus, Norwalk, Connecticut).

\section{Statistical Analysis}

Descriptive statistics were calculated with their 95\% confidence intervals. The associations between the clinicopathologic features and p63 IR were evaluated by means of the $\chi^{2}$ test with Yates' correction and the $\chi^{2}$ test for trend in the case of ordinal variables. The prognostic relevance of the patients' baseline characteristics to disease-free survival and overall mortality (death caused by cancer and other causes) were assessed by means of survival analysis based on the Kaplan-Meier product limit estimate of the cumulative probability survival function. The follow-up of the patients was truncated at 13 years (with more than $20 \%$ of the starting sample cases still at risk), to obtain satisfactorily precise probability estimates. The prognostic relevance of p63 IR was assessed using two classes ( $\leq 50$ and $>50 \%$ ). The other investigated prognostic factors were classified as follows: age at diagnosis: $\leq 60$ years and $>60$ years; smoking exposure: $0-19,20-45$, and $>45$ pack-years; alcohol consumption: $\geq 7$ drinks per day and $<7$ drinks per day/nondrinkers; histologic grade: G1, G2, and G3; lymph node metastasis: presence and absence; tumor extension: T1-T2 and T3-T4; and clinical stage: I-II and
III-IV. The disease-free and overall survival functions of the different classes of investigated variables were compared using the log-rank test. In the case of ordinal variables, in addition to the overall log-rank statistic, the pertinent test for trend was also made. Multivariate analyses of overall and disease-free survival was made using the proportional hazard Cox's model according to a backward procedure.

\section{References}

Barbareschi M, Pecciarini L, Cangi MG, Macri E, Rizzo A, Viale G, and Doglioni C (2001). p63, a p53 homologue, is a selective nuclear marker of myoepithelial cells of the human breast. Am J Surg Pathol 25:1054-1060.

Gaiddon C, Lokshin M, Ahn J, Zhang T, and Prives C (2001). A subset of tumor-derived mutant forms of p53 downregulate $p 63$ and p73 through a direct interaction with the p53 core domain. Mol Cell Biol 21:1874-1887.

Glickman JN, Yang A, Shahsafaei A, McKeon F, and Odze $\mathrm{RD}$ (2001). Expression of p53-related protein p63 in the gastrointestinal tract and in esophageal metaplastic and neoplastic disorders. Hum Pathol 32:1157-1165.

Hagiwara K, McMenamin MG, Miura K, and Harris CC (1999). Mutational analysis of the p63/p73L/p51/p40/CUSP/KET gene in human cancer cell lines using intronic primers. Cancer Res 59:4165-4169.

Hibi K, Trink B, Patturajan M, Westra WH, Caballero OL, Hill DE, Ratovitski EA, Jen J, and Sidransky D (2000). AIS is an oncogene amplified in squamous cell carcinoma. Proc Natl Acad Sci USA 97:5462-5467.

Irwin MS and Kaelin WG (2001). p53 family update: p73 and p63 develop their own identities. Cell Growth Differ 12:337349.

Levrero M, De Laurenzi V, Costanzo A, Gong J, Wang JY, and Melino G (2000). The p53/p63/p73 family of transcription factors: Overlapping and distinct functions. J Cell Sci 113: 1661-1670.

Manzotti M, Dell'Orto P, Maisonneuve P, Fornaro M, Languino LR, and Viale G (2000). Down-regulation of beta(1C) integrin in breast carcinomas correlates with high proliferative fraction, high histological grade, and larger size. Am J Pathol 156:169-174.

Mills AA, Zheng B, Wang XJ, Vogel H, Roop DR, and Bradley A (1999). p63 is a p53 homologue required for limb and epidermal morphogenesis. Nature 398:708-713.

Neri A, Baldini L, Trecca D, Cro L, Polli E, and Maiolo AT (1993). p53 gene mutations in multiple myeloma are associated with advanced forms of malignancy. Blood 81:128-135.

Nishi H, Isaka K, Sagawa Y, Usuda S, Fujito A, Ito H, Senoo M, Kato H, and Takayama M (1999). Mutation and transcription analyses of the p63 gene in cervical carcinoma. Int J Oncol 15:1149-1153

Nylander K, Coates PJ, and Hall PA (2000). Characterization of the expression pattern of $\mathrm{p} 63 \alpha$ and $\Delta \mathrm{Np} 63$ alpha in benign and malignant oral epithelial lesions. Int $\mathrm{J}$ Cancer 87:368372.

Park BJ, Lee SJ, Kim JI, Lee SJ, Lee CH, Chang SG, Park JH, and Chi SG (2000). Frequent alteration of p63 expression in human primary bladder carcinomas. Cancer Res 60:33703774. 
Pelosi G, Pasini F, Stenholm CO, Pastorino U, Maisonneuve P, Sonzogni A, Maffini F, Pruneri G, Fraggetta F, Cavallon A, Roz E, lannucci A, Bresaola E, and Viale G (2002). p63 immunoreactivity in lung cancer: Yet another player in the development of squamous cell carcinomas? J Pathol 198: 100-109.

Pruneri G, Fabris S, Baldini L, Carboni N, Zagano S, Colombi MA, Ciceri G, Lombardi L, Rocchi M, Buffa R, Maiolo AT, and Neri A (2000). Immunohistochemical analysis of cyclin D1 shows deregulated expression in multiple myeloma with the $\mathrm{t}(11 ; 14)$. Am J Pathol 156:1505-1513.

Pruneri G, Pignataro L, Carboni N, Ronchetti D, Cesana BM, Ottaviani A, Neri A, and Buffa R (1998). Clinical relevance of p53 and bcl-2 protein over-expression in laryngeal squamous-cell carcinoma. Int J Cancer 79:263-268.

Pruneri G, Pignataro L, Fracchiolla NS, Ferrero S, Capaccio P, Carboni N, Ottaviani A, Maiolo AT, Neri A, and Buffa R (1996). p53 protein expression in laryngeal squamous cell carcinomas bearing wild-type and mutated p53 gene. Histopathology 28:513-519.

Shanmugaratnam K and Sobin LN (1987). Histological typing of tumours of the upper aerodigestive tract and ear, 2 nd ed. Berlin: Springer.

Speicher MR, Howe C, Crotty P, du Manoir S, Costa J, and Ward DC (1995). Comparative genomic hybridization detects novel deletions and amplifications in head and neck squamous cell carcinomas. Cancer Res 55:1010-1013.

Suliman Y, Opitz OG, Avadhani A, Burns TC, El-Deiry W, Wong DT, and Rustgi AK (2001). p63 expression is associated with p53 loss in oral-esophageal epithelia of p53deficient mice. Cancer Res 61:6467-6473.
Sunahara M, Shishikura T, Takahashi M, Todo S, Yamamoto $\mathrm{N}$, Kimura $\mathrm{H}$, Kato $\mathrm{S}$, Ishioka $\mathrm{C}$, Ikawa S, Ikawa $\mathrm{Y}$, and Nakagawara A (1999). Mutational analysis of p51A/ TAp63gamma, a p53 homolog, in non-small cell lung cancer and breast cancer. Oncogene 18:3761-3765.

Tani M, Shimizu K, Kawahara C, Kohno T, Ishimoto O, Ikawa $\mathrm{S}$, and Yokota J (1999). Mutation and expression of the p51 gene in human lung cancer. Neoplasia 1:71-79.

UICC. TNM classification of malignant tumors (1987). Hermanek P and Sobin LH, editors. Berlin: Springer.

Yamaguchi K, Wu L, Caballero OL, Hibi K, Trink B, Resto V, Cairns P, Okami K, Koch WM, Sidransky D, and Jen J (2000). Frequent gain of the p40/p51/p63 gene locus in primary head and neck squamous cell carcinoma. Int J Cancer 86:684689 .

Yang A, Kaghad M, Wang Y, Gillett E, Fleming MD, Dotsch V, Andrews NC, Caput D, and McKeon F (1998). p63, a p53 homolog at 3q27-29, encodes multiple products with transactivating, death-inducing, and dominant-negative activities. Mol Cell 2:305-316.

Yang A, Schweitzer R, Sun D, Kaghad M, Walker N, Bronson RT, Tabin C, Sharpe A, Caput D, Crum C, and McKeon F (1999). p63 is essential for regenerative proliferation in limb, craniofacial and epithelial development. Nature 398:714718.

Wang TY, Chen BF, Yang YC, Chen H, Wang Y, Cviko A, Quade BJ, Sun D, Yang A, McKeon FD, and Crum CP (2001). Histologic and immunophenotypic classification of cervical carcinomas by expression of the p53 homologue p63: A study of 250 cases. Hum Pathol 32:479-486. 